\title{
WPLYW PODWYŻSZONEJ TEMPERATURY NA SKUTECZNOŚĆ WZMOCNIENIA BELEK ŻELBETOWYCH TAŚMAMI TYPU CFRP I SRP
}

\begin{abstract}
Klejenie zewnętrznych nakładek kompozytowych zbrojonych włóknami wysokiej wytrzymałości powoli staje się najpopularniejszą metodą wzmacniania konstrukcji żelbetowych. Zdarza się, że tego typu wzmocnienia mogą być bezpośrednio poddane nasłonecznieniu i tym samym zagrożone nadmiernym nagrzaniem. Badania prowadzone przez autora artkułu pokazały, że nawet w umiarkowanej strefie geograficznej, w której znajduje się Polska, temperatura kleju pod cienkim laminatem może osiągnąc $65^{\circ} \mathrm{C}$, czyli temperaturę o $20^{\circ} \mathrm{C}$ wyższą niż temperatura zeszklenia najpopularniejszych na rynku klejów opartych na żywicy epoksydowej. W artykule przedstawiono wyniki badań laboratoryjnych belek żelbetowych podgrzanych od strony wzmocnienia promieniowaniem podczerwonym. Program badań objął grupę trzynastu belek żelbetowych w skali rzeczywistej. Sześć z nich zostało wzmocnionych taśmą CFRP, kolejnych sześć z taśmą SRP. Belki podgrzewano za pomocą liniowych promienników podczerwieni do mierzonej $\mathrm{w}$ warstwie adhezyjnej temperatury od $20^{\circ} \mathrm{C}$ do $80^{\circ} \mathrm{C}$. Po jej osiągnięciu belki obciążano do zniszczenia w teście czteropunktowego zginania. Zauważalny spadek nośności obserwowano już dla temperatury $50^{\circ} \mathrm{C}$. Nie stosowano mechanicznego kotwienia, dlatego przyczyną uszkodzenia we wszystkich przypadkach była delaminacja, zazwyczaj w warstwie kleju. Belki wzmocnione taśmą CFRP niszczyły się gwałtownie, bez szczególnych symptomów dźwiękowych towarzszących delaminacji. Ich nośność w temperaturach powyżej $65^{\circ} \mathrm{C}$ była bliska nośności nie wzmocnionej belki referencyjnej. Nieco korzystniej zachowywały się belki wzmocnione taśmą SRP, głównie dzięki większej szerokości i tym samym niższym naprężeniem w warstwie kleju.
\end{abstract}

Słowa kluczowe: wzmocnienie kompozytowe, CFRP, SRP, temperatura zeszklenia, żywica epoksydowa, przyczepność

\section{Wprowadzenie}

Współczesne wzmocnienia konstrukcji budowlanych coraz częściej wykorzystują kompozyty zbrojone włóknami wysokiej wytrzymałości. Zazwyczaj elementem scalającym włókna tych kompozytów, a także spajającym je ze wzmacnianą konstrukcją są kleje oparte na żywicach epoksydowych. Ze wzglę-

\footnotetext{
${ }^{1}$ Rafał Krzywoń, Politechnika Śląska, Katedra Inżynierii Budowlanej, ul. Akademicka 5, 44-100 Gliwice; tel. 322372262; rafal.krzywon@polsl.pl
} 
du na właściwości i cenę tego typu polimery są znane w budownictwie od wielu lat. Niewątpliwie ich największą wadą, szczególnie istotną w przypadku zewnętrznych nakładek wzmacniających, jest stosunkowo niska temperatura zeszklenia, niekiedy określana już dla temperatur około $40 \div 50^{\circ} \mathrm{C}$ [1]. W tym zakresie temperatury polimer epoksydowy zaczyna zmieniać swoje właściwości, ze stanu ciała stałego, który bywa również określany jako szklisty, na stan bliższy ciału plastycznemu lub cieczy. W fazie pośredniej jego właściwości można ocenić jako lepko-sprężyste. W konsekwencji tego zjawiska, materiały bazujące na epoksydach, w tym kompozytowe nakładki wzmacniające, należy traktować jako mało odporne na podwyższone temperatury. Zjawisko to, początkowo niedoceniane, a nawet lekceważone przez producentów systemów wzmacniających, jest coraz częściej zauważane i badane, również w Polsce [2]. Co najważniejsze, problem może dotyczyć nie tylko sytuacji pożaru, ale również zwykłego nagrzania w promieniach słońca. Nawet niewielkie płynięcie kleju może skutkować relaksacją naprężeń w systemie wzmacniającym, pogorszeniem efektywności wzmocnienia i wzrostem ugięć. W skrajnym przypadku obciążenia krytycznego, może doprowadzić również do delaminacji przyklejonej nakładki, zmniejszenia nośności i niebezpiecznego uszkodzenia elementu na odcinku wzmocnienia.

Określenie temperatura zeszklenia dotyczy pewnego zakresu temperatur, w którym dochodzi to przemiany fazowej polimeru. W przypadku epoksydów pełny proces odkszklenia zachodzi $\mathrm{w}$ zakresie przyrostu temperatury przynajmniej $10 \div 20^{\circ} \mathrm{C}$ [3], przy czym zależy on od takich czynników jak liczba potencjalnych powiązań w łańcuchu polimerowym, czy też układu tych powiązań [4]. Jako, że sam proces polimeryzacji jest zjawiskiem długotrwałym, to w praktyce temperatura zeszklenia rośnie wraz z wiekiem epoksydu. Osiągnięcie ,dojrzałości” polimeru można przyspieszyć przez wygrzewanie w początkowym okresie utwardzania, a za optymalną temperaturę takiej obróbki uznaje się $60^{\circ} \mathrm{C}$ [5]. Tydzień utwardzania w takiej temperaturze równoważy 17-letnie wiązanie w warunkach pokojowych [6]. Podobny efekt nagrzania może wystąpić wskutek działania promieni słonecznych. Dzięki temu żywice w warunkach zewnętrznych, zwłaszcza latem, kiedy temperatury przekraczają $30^{\circ} \mathrm{C}$, ulegają lepszemu utwardzeniu, uzyskując wyższe temperatury zeszklenia niż modele laboratoryjne [1]. $\mathrm{W}$ trakcie utwardzania w podwyższonej temperaturze nie jest wskazane obciążanie warstwy kleju, czyli wzmocniony element musi pozostać odciążony w całym przewidzianym okresie utwardzania. Niekorzystny wpływ na temperaturę zeszklenia ma również wilgotność, co wiąże się ze zmniejszeniem sił Van der Valsa pomiędzy cząsteczkami polimeru [4].

Przemiana fazowa utwardzonej żywicy epoksydowej w ciało lepkosprężyste prowadzi do pogorszenia jej właściwości mechanicznych, co dla samego kompozytu oznacza pogorszenie współpracy pomiędzy włóknami zbrojenia, natomiast dla przyklejonej nakładki kompozytowej powoduje zmniejszenie jej przyczepności do wzmacnianego elementu. Jak wykazują dotychczasowe badania, gwałtowny spadek przyczepności współcześnie stosowanych klejów 
rozpoczyna się około $60^{\circ} \mathrm{C}$ [7]. Długości odcinka, na którym zostają przekazane siły przyczepności (odcinek zakotwienia) rośnie około 2,5 $\div 3$ krotne [8]. Najprawdopodobniej w konsekwencji lepszego utwardzenia żywicy epoksydowej, temperatury do $50^{\circ} \mathrm{C}$ korzystnie wpływają na przyczepność kleju, która rośnie w porównaniu do próbek badanych w temperaturze pokojowej $[9,10]$.

\section{Wpływ nasłonecznienia na temperaturę laminatu FRP}

Latem 2015 roku autor referatu prowadził badania nagrzania warstwy kleju epoksydowego dla różnych typów zewnętrznych laminatów kompozytowych na podłożach betonowym i drewnianym. W szczególności badania objęły: taśmę CFRP o przekroju $60 \times 1,4 \mathrm{~mm}$, pojedynczą warstwę laminatu z maty CFRP, taśmę SRP (Steel Reinforced Polymer) Hardwire typu 3×2-12 o powierzchni niewykończonej i powierzchni piaskowanej. Próbki układano na płaskiej powierzchni, w otwartej, niezacienionej i nieosłoniętej przestrzeni. Pomiary prowadzono w wybranych słonecznych dniach czerwca, lipca i sierpnia. Pomiary temperatury, a dokładniej pomiary prędkości przyrostu temperatury, prowadzono w odstępach godzinnych, a w okresie wczesnopopołudniowym w odstępach półgodzinnych i krótszych.

Szczegółowe wyniki badań zebrano w pracy [11]. Zazwyczaj już po około $3 \div 4$ godzinach temperatura w warstwie kleju przekraczała $50^{\circ} \mathrm{C}$. Zaobserwowano również, że stopień nagrzania próbek zależy w większym stopniu od intensywności promieniowania słonecznego, niż temperatury powietrza. Zazwyczaj maksymalne temperatury występowały w pobliżu godziny czternastej. Sprzyjały im bezchmurne niebo oraz brak wiatru.

Najwyższe temperatury, przekraczające $70^{\circ} \mathrm{C}$, odnotowano w warstwie kleju pod taśmą CFRP na podłożu drewnianym. Średnio były one nawet $10^{\circ} \mathrm{C}$ wyższe niż dla porównywalnych modeli na podłożu betonowym, co należy wiązać z lepszą izolacyjnością termiczną drewna, ograniczającą odbiór ciepła z powierzchni. Maksymalna zmierzona temperatura wśród próbek betonowych wyniosła $64^{\circ} \mathrm{C}$. Generalnie, najprawdopodobniej z uwagi na czarny kolor, próbki CFRP nagrzewały się bardziej niż jasnoszary laminat SRP.

\section{Badania belek zginanych podgrzewanych od strony nakładki wzmacniającej}

Program badań objął grupę trzynastu belek żelbetowych, w tym:

- jedną belkę referencyjną bez wzmocnienia,

- sześć belek wzmocnionych taśmami węglowymi CFK 200/2000 o przekroju $60 \times 1,4 \mathrm{~mm}$,

- sześć belek wzmocnionych taśmami stalowymi typu Hardwire® SRP typu $3 \times 2-20$ o szerokości $150 \mathrm{~mm}$. 
Celem badań było określenie możliwego wpływu intensywnego nasłonecznienia na nośność, ugięcie i rysoodporność belek oraz porównanie tych cech dla belek z dwoma konkurencyjnymi typami zbrojenia - prefabrykowaną taśmą z włókien węglowych oraz laminatem zbrojonym splotami drutów małej średnicy ze stali o ultra-wysokiej wytrzymałości.

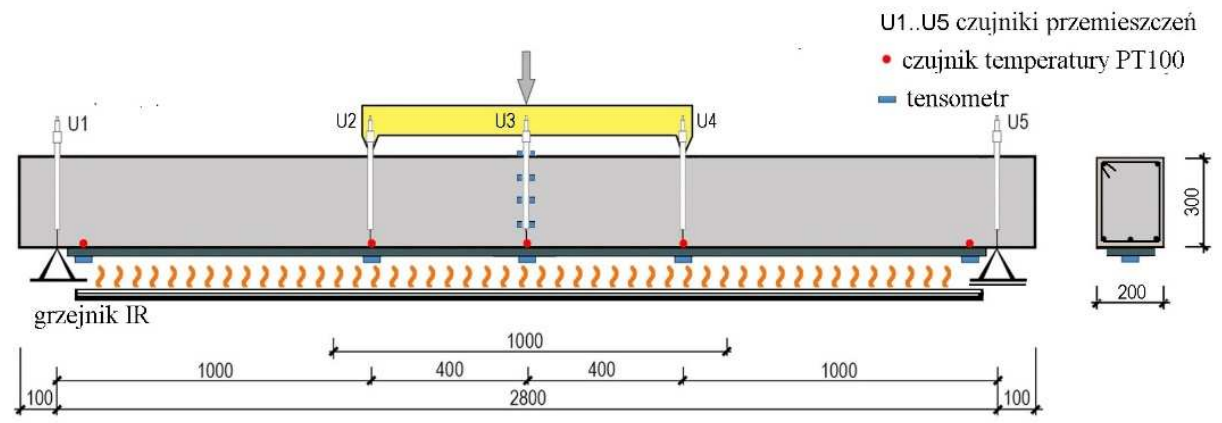

Rys. 1. Schemat badania belki wzmocnionej kompozytem i podgrzewanej

Fig. 1. Test lay-out of strengthened and heated beam

Schemat badania pokazano na rys. 1. Belki o przekroju poprzecznym 200×300 mm wykonano z jednego zarobu betonu towarowego, dla którego zbadane podstawowe właściwości wytrzymałościowe zestawiono w tabeli 1.

Belki zbrojono prętami żebrowanymi, w dolnej strefie trzy pręty \#12, w strefie górnej dwa pręty \#10, strzemiona \#6 w rozstawione co $100 \mathrm{~mm}$ (w strefie środkowej co $200 \mathrm{~mm}$ ). Właściwości stali zestawiono w tabeli 2. $\mathrm{W}$ tabeli 3. porównano cechy nakładek kompozytowych wykorzystanych do wzmocnienia. Oba typy taśm zostały przyklejone klejem Sikadur®330 (zalecanym przez producenta taśm SRP). Belki badano po $40 \div 50$ dniach od przyklejenia wzmocnienia, przy czym nie stosowano żadnych dodatkowych zabiegów przyspieszających utwardzanie kleju (wygrzewanie itp.).

Tabela 1. Właściwości wytrzymałościowe betonu zastosowanego do wykonania belek

Table 1. Strength properties of concrete used for production of beams

\begin{tabular}{|c|c|c|c|}
\hline $\begin{array}{c}\text { Średnia wytrzyma- } \\
\text { tość kostkowa na } \\
\text { ściskanie } \\
{[\mathbf{M P a}]}\end{array}$ & $\begin{array}{c}\text { Średnia wytrzyma- } \\
\text { łość słupowa na } \\
\text { ściskanie } \\
{[\mathbf{M P a}]}\end{array}$ & $\begin{array}{c}\text { Średnia wytrzyma- } \\
\text { tość na rozciąganie } \\
{[\mathbf{M P a}]}\end{array}$ & $\begin{array}{c}\text { Sieczny moduł } \\
\text { sprężystości } \\
\text { [GPa] }\end{array}$ \\
\hline 44,7 & 40,3 & 3,2 & 30,7 \\
\hline
\end{tabular}


Tabela 2. Właściwości stali zbrojeniowej zastosowanej w badanych belkach

Table 2. Properties of reinforcing steel used in tested beams

\begin{tabular}{|c|c|c|c|}
\hline $\begin{array}{c}\text { Średnica } \\
\text { pręta }\end{array}$ & $\begin{array}{c}\text { Granica plastyczno- } \\
\text { ści } \\
{[\mathbf{M P a}]}\end{array}$ & $\begin{array}{c}\text { Średnia wytrzymałość } \\
\text { na rozciąganie } \\
{[\mathbf{M P a}]}\end{array}$ & $\begin{array}{c}\text { Moduł sprężystości } \\
\text { [GPa] }\end{array}$ \\
\hline$\# 12$ & 588 & 635 & 200,7 \\
\hline$\# 10$ & 570 & 661 & 200,7 \\
\hline
\end{tabular}

Tabela 3. Właściwości taśm kompozytowych zastosowanych do wzmocnienia belek

Table 3. Properties of composite overlays used in tested beams

\begin{tabular}{|c|c|c|c|}
\hline Rodzaj taśmy & $\begin{array}{c}\text { Powierzchnia } \\
\text { nominalna } \\
{\left[\mathbf{m m}^{\mathbf{2}}\right]}\end{array}$ & $\begin{array}{c}\text { Średnia wytrzyma- } \\
\text { tość na rozciąganie } \\
{[\mathbf{M P a}]}\end{array}$ & $\begin{array}{c}\text { Moduł sprężystości } \\
{[\mathbf{G P a}]}\end{array}$ \\
\hline CFRP 200/2000 & 84 & 2577 & 204 \\
\hline SRP 3x2-20 & 57 & 3302 & 201 \\
\hline
\end{tabular}

Belki badano stosując test czteropunktowego zginania. Przed testem belki podgrzewano stosując liniowe promienniki podczerwieni, aby zachować warunki zbliżone do nasłonecznienia. Po osiągnieciu żądanej temperatury belki obciążano do zniszczenia. W początkowej fazie badania kontynuowano podgrzewanie, jednakże w końcowej fazie, z uwagi na gwałtowną postać zniszczenia i niebezpieczeństwo uszkodzenia grzejników, demontowano je, co niestety skutkowało niepożądanym spadkiem temperatury o około $10^{\circ} \mathrm{C}$.

\section{Wyniki badań}

W trakcie badania zadawano obciążenie i mierzono przemieszczenie za pomocą czujników indukcyjnych w pięciu punktach (rys. 1.) oraz odkształcenia w przekroju środkowym i w pięciu charakterystycznych punktach wzdłuż dolnej powierzchni belki. Dodatkowo inwentaryzowano rysy oraz mierzono ich rozwarcie w trakcie, kiedy belka była podgrzewana. Ze względu na dość szybki spadek temperatury po usunięciu grzejników, prowadzono obciążenie do zniszczenia bez czasochłonnej inwentaryzacji rys. Wybrane, najistotniejsze wyniki badań zebrano w tabelach 4. i 5. Wyniki zamieszczone w tabeli 5 odniesiono do obciążenia $90 \mathrm{kN}$, które jest obciążeniem niszczącym dla belki referencyjnej, natomiast dla belek wzmocnionych, może być traktowane jako obciążenie użytkowe (60\% nośności).

Analiza przedstawionych wyników pokazuje, że w zakresie obciążeń użytkowych wpływ temperatury jest znikomy. Dotyczy to zarówno ugięć, odkształceń laminatu oraz rozwoju zarysowań. Pierwsze rysy pojawiały się przy obciążeniu $25 \div 30 \mathrm{kN}$. Widoczne różnice pojawiają się dopiero po uplastycznieniu zbrojenia zwykłego, czyli gdy dalszy przyrost nośności zależy wyłącznie od efektywności pracy nakładki wzmacniającej. 
Tabela 4. Wyniki badań belek żelbetowych dla obciążenia niszczącego

Table 4. Test results of RC beams at failure force

\begin{tabular}{|c|c|c|c|c|c|}
\hline 祬 & 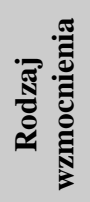 & 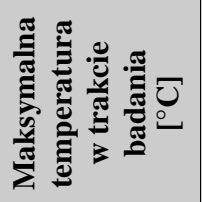 & 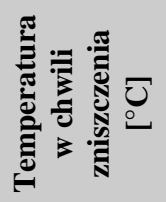 & 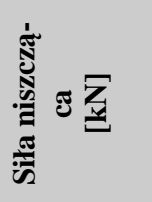 & 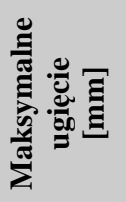 \\
\hline REF & brak & 21 & 21 & 99,2 & $>71^{*}$ \\
\hline CFRP_1 & \multirow{6}{*}{ 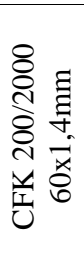 } & 21 & 21 & 139,6 & 20,5 \\
\hline CFRP_2 & & 21 & 21 & 145 & 21,2 \\
\hline CFRP_T51 & & 51 & 44 & 135,6 & 20,4 \\
\hline CFRP_T56 & & 56 & 45 & 134,6 & 20,6 \\
\hline CFRP_T62 & & 62 & 51 & 131,6 & 21,3 \\
\hline CFRP_T73 & & 73 & 67 & 110,8 & 13,3 \\
\hline SRP_1 & \multirow{6}{*}{ 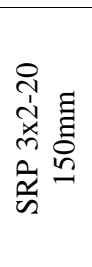 } & 21 & 21 & 152,8 & 29,1 \\
\hline SRP_2 & & 21 & 21 & 150,6 & 28,5 \\
\hline SRP_T37 & & 37 & 32 & 166,8 & 35,2 \\
\hline SRP_T64 & & 64 & 56 & 145,2 & 30,5 \\
\hline SRP_T69 & & 69 & 59 & 127,6 & 24,7 \\
\hline SRP_T80 & & 80 & 68 & 129,8 & 23,7 \\
\hline
\end{tabular}

* ostatni pomiar na którym zakończono badanie

Tabela 5. Wyniki badań belek żelbetowych dla obciążenia $90 \mathrm{kN}$

Table 5. Test results of RC beams at force of $90 \mathrm{kN}$

\begin{tabular}{|c|c|c|c|c|c|}
\hline 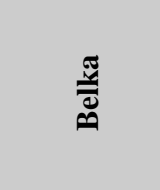 & 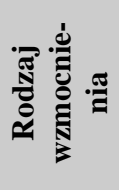 & 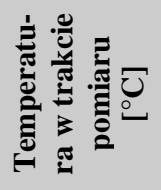 & 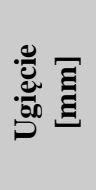 & 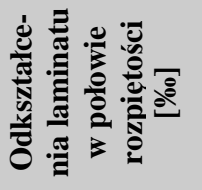 & 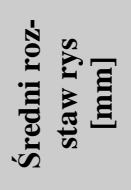 \\
\hline REF & brak & 21 & 13,7 & - & 95 \\
\hline CFRP_1 & \multirow{6}{*}{ 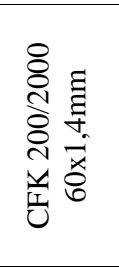 } & 21 & 9,5 & 2,36 & 69 \\
\hline CFRP_2 & & 21 & 9,6 & 2,41 & 88 \\
\hline CFRP_T51 & & 51 & 10,0 & 2,38 & 82 \\
\hline CFRP_T56 & & 56 & 10,2 & 2,36 & 80 \\
\hline CFRP_T62 & & 62 & 10,1 & 2,37 & 100 \\
\hline CFRP_T73 & & 73 & 10,1 & 2,29 & 98 \\
\hline SRP_1 & \multirow{6}{*}{ 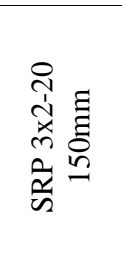 } & 21 & 9,8 & 2,32 & 79 \\
\hline SRP_2 & & 21 & 10,2 & 2,49 & 95 \\
\hline SRP_T37 & & 37 & 9,3 & 2,23 & 110 \\
\hline SRP_T64 & & 64 & 9,1 & 1,73 & 92 \\
\hline SRP_T69 & & 69 & 10,1 & 1,87 & 77 \\
\hline SRP_T80 & & 80 & 10,3 & 2,03 & 107 \\
\hline
\end{tabular}


Prowadzone przez Mousa i in. [6] badania próbek kleju Sikadur®330 utwardzanego $\mathrm{w}$ warunkach laboratoryjnych wykazały początkową temperaturę zeszklenia na poziomie $43^{\circ} \mathrm{C}$, a po upływie roku jej wzrost do $56^{\circ} \mathrm{C}$, natomiast po siedmiu latach do $62^{\circ} \mathrm{C}$. Ponieważ przedmiotowe belki zbadano po około 50 dniach od zastosowania wzmocnienia, temperaturę zeszklenia zastosowanego kleju można oszacować na niecałe $50^{\circ} \mathrm{C}$. Potwierdzają to pomiary nośności, gdyż już dla belki CFRP_T51 charakteryzuje niewielki spadek nośności. $\mathrm{W}$ temperaturach do około $65^{\circ} \mathrm{C}$ nośność belek, w porównaniu do badanych w temperaturze pokojowej zmniejsza się maksymalnie o 8\% (odniesiony do belki referencyjnej REF spadek efektywności wzmocnienia wynosi $25 \%$ ). W temperaturach powyżej $65^{\circ} \mathrm{C}$ spadek efektywności wzmocnienia zdecydowanie przyspiesza. Dla belki SRP_T69 wynosi 46\%, natomiast aż 73\% dla belki CFRP_T73.

Początek płynięcia kleju potwierdza również forma zniszczenia. Wprawdzie dla wszystkich badanych belek była to delaminacja, jednakże w belkach badanych w niższych temperaturach zachodziła ona na styku struktury betonu i kleju. Zdarzało się, że taśma odspajała się z całymi fragmentami otuliny. $\mathrm{W}$ belkach badanych $\mathrm{w}$ temperaturach powyżej $65^{\circ} \mathrm{C}$ powierzchnia taśmy była praktycznie wolna od ziaren betonu (rys. 2.), co wskazuje na spadek przyczepności kleju poniżej wytrzymałości betonu na rozciąganie.
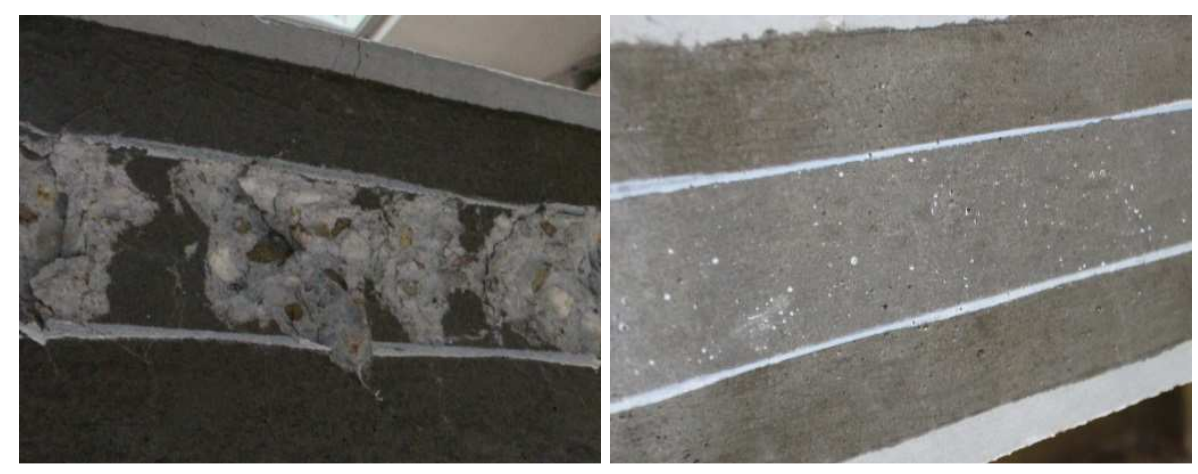

Rys. 2. Powierzchnia belki żelbetowej po delaminacji (a) belka CFRP_T56; (b) belka CFRP_T73

Fig. 2. RC Beam's surface after delamination (a) beam CFRP_T56; (b) beam CFRP_T73

Badania potwierdziły również obserwowany przez innych badaczy $[9,10]$ korzystny wpływ temperatury nieco niższej od temperatury zeszklenia. Nośność belki SRP_T37 badanej w $37^{\circ} \mathrm{C}$ jest prawie $10 \%$ wyższa niż belek badanych $\mathrm{w}$ temperaturze pokojowej.

Porównując belki wzmocnione taśmą CFRP i SRP, można zauważyć zdecydowanie większą wrażliwość na temperaturę belek z przyklejonym kompozytem węglowym. Należy to łączyć z 2,5 krotnie większą szerokością taśmy SRP i tym samym powierzchnią spoiny klejowej, a w konsekwencji ze znacznie mniejszym jej obciążeniem siłami przyczepności. 

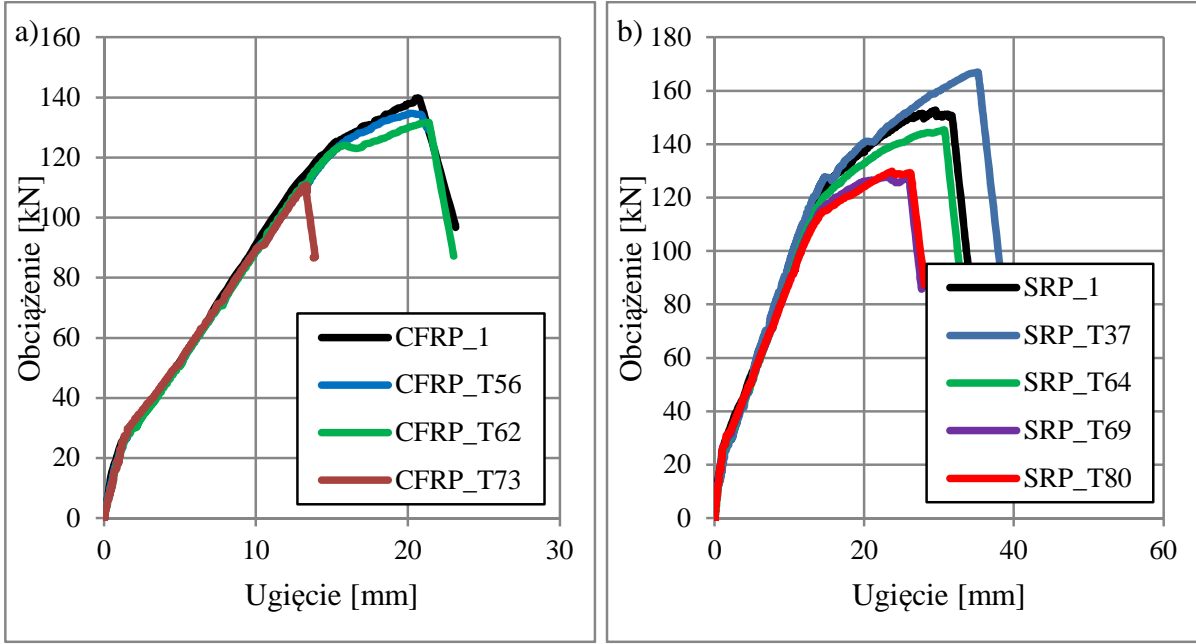

Rys. 3. Przyrost ugięcia belek (a) wzmocnionych taśmą CFRP; (b) wzmocnionych taśmą SRP

Fig. 3. Change of deflection (a) beam strengthened with CFRP strip; (b) beam strengthened with SRP tape
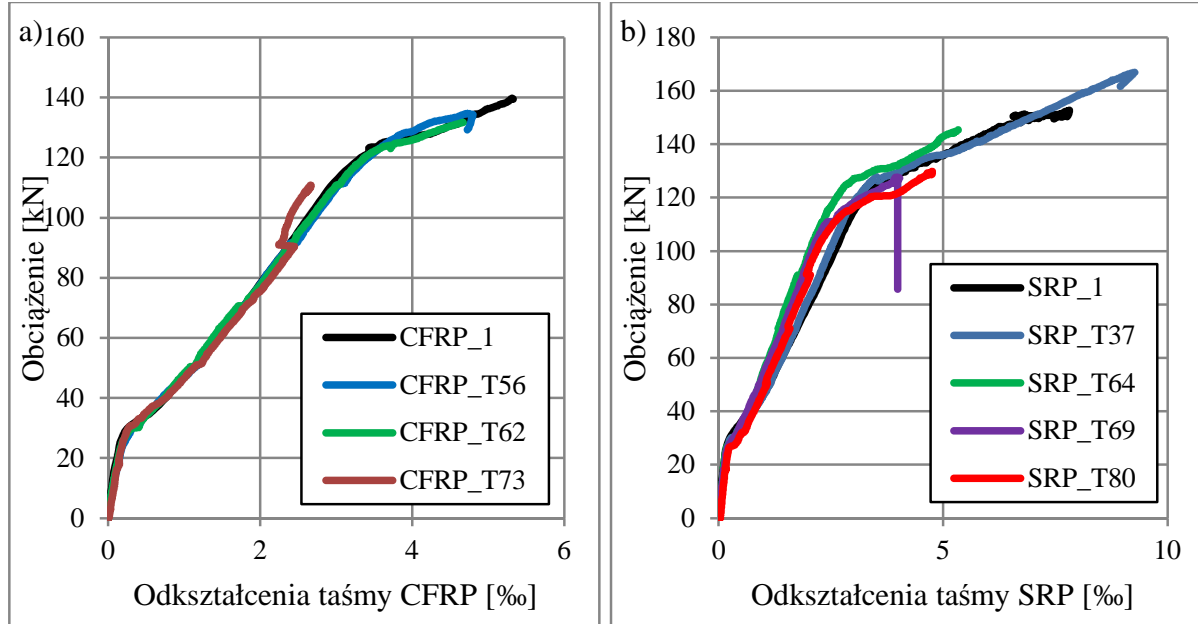

Rys. 4. Przyrost odkształceń taśm w środku rozpiętości (a) CFRP; (b) SRP

Fig. 4. Change of strains at midspan (a) CFRP strip; (b) SRP tape

Temperatura w bardzo niewielkim stopniu wpływa na ugięcie. Należy jednak podkreślić, że jedynie aktywne wzmocnienie (sprężenie) skutecznie ogranicza ugięcie. Wzmocnienie pasywne jest mniej efektywne, z uwagi na relatywnie nieduży wzrost sztywności, wynikający z niewielkiego przekroju nakładki kompozytowej. Pomimo tego, tendencja do wzrostu ugięć w wyższych temperatu- 
rach jest wyraźnie zauważalna, zwłaszcza w przypadku belek wzmacnianych taśmą SRP (rys. 3.a). Takie zachowanie można tłumaczyć relaksacją taśmy w wyniku poślizgu w płaszczyźnie kleju. Pośrednio dowodzi tego analiza odkształceń taśmy, które w przypadku modeli badanych w wyższych temperaturach są mniejsze (tab. 5., rys. 4.).

\section{Wnioski}

W referacie opisano badania belek żelbetowych wzmacnianych taśmami kompozytowymi typu SRP i CFRP, ogrzewanych w sposób imitujący ekspozycję słoneczną. Badania wykazały, że już w temperaturach niewiele przekraczających $50^{\circ} \mathrm{C}$ można zaobserwować postępujące osłabienie przyczepności użytego kleju epoksydowego. Wynika ono z przemiany fazowej po osiągnięciu temperatury zeszklenia. Niekorzystny wpływ temperatury nasila się powyżej $65^{\circ} \mathrm{C}$.

Belki wzmocnione taśmą węglową okazały się bardziej wrażliwe na podwyższoną temperaturę, niż belki wzmocnione kompozytem SRP. Wynika to z różnej szerokości obu typów taśm.

Wszystkie modele zniszczyły się w wyniku delaminacji, jednakże w wyższej temperaturze jej przebieg był gwałtowny i nie poprzedzały go charakterystyczne trzaski pękającego laminatu. W wyższych temperaturach delaminacja następowała w warstwie kleju.

\section{Literatura}

[1] Michels J., Widmann R., Czaderski C., Allahvirdizadeh R., Motavalli M.: Glass transition evaluation of commercially available epoxy resins used for civil engineering applications, Composites Part B 77, 2015, pp. 484-493.

[2] Trapko T.: The effect of high temperature on the performance of CFRP and FRCM confined concrete elements, Composites Part B 54, 2013, 138-145.

[3] Hülder G., Dallner C., Ehrenstein G.W.: Curing of epoxy-adhesives for the supplementary reinforcement of buildings with bonded CFRP-straps (in German), Bauingenieur 81, 2006, pp. 449-454.

[4] Othman D., Stratford T.J., Bisby L.A.: A Comparison of On-Site and Elevated Temperature Cure of an FRP Strengthening Adhesive, Proceedings of the FRPRCS11, UM, Guimarães, 2013.

[5] Carbas R.J.C., Marques E.A.S., Lopes A.M., da Silva L.F.M.: Effect of cure temperature on the glass transition temperature of an epoxy adhesive, Proceedings of the 15th International Conference on Experimental Mechanics ICEM2015, University of Porto 2012.

[6] Moussa O., Vassilopoulos A.P., Castro J.D., Keller T.: Long-term development of thermophysical and mechanical properties of cold-curing structural adhesives due to post-curing. Journal of Applied Polymer Science 2013;127(4), str. 2490-2496.

[7] Tadeu A., Branco F., Shear tests of steel plates epoxy bonded to concrete under temperature, Journal of Materials in Civil Engineering 2000, 12(1), pp. 74-80. 
[8] Leone M., Matthys S., Aiello M.A.: Effect of elevated service temperature on bond between FRP EBR systems and concrete, Composites: Part B 40 (2009), p. 85-93.

[9] Blontrock H., Taerwe L., Vanwalleghem H.: Bond testing of externally glued FRP laminates at elevated temperature, Proceeding of the international conference: Bond in concrete- from research to standard, Budapest, Hungary, 2002, pp. 648-654.

[10] Klamer E.L., Hordijk D.A., Kleinman C.S.: Debonding of CFRP laminates externally bonded to concrete specimens at low and high temperatures, Proceedings of Third International Conference on FRP Composites in Civil Engineering (CICE 2006), Miami, Florida, USA, pp. 35-38.

[11] Krzywoń R., Temperature in the adhesive layer of externally bonded composite reinforcement heated by the sun, ACEE Archit. Civ. Eng. Environ. 2016, Vol. 9, No. 1, pp. 79-84.

\section{INFLUENCE OF ELEVATED TEMPERATURE ON EFFICIENCY OF RC BEAMS STRENGTHENING WITH CFRP STRIPS AND SRP TAPES}

\section{S u m m a r y}

Bonding of external composite overlays reinforced with high-strength fibers becomes the most popular technique of strengthening the reinforced concrete structures. Some of those strengthening overlays may be exposed to direct sunlight and thus threatened by excessive heating. Researches provided by the author of this paper showed that even for the location of Poland and the northern continental zone, the adhesive temperature under a thin FRP laminate may reach $65^{\circ} \mathrm{C}$, about $20^{\circ} \mathrm{C}$ more than the glass transition temperature of the based on epoxy resin, most popular adhesives available on the market. The paper presents the results of laboratory tests of reinforced concrete beams heated along the bottom, reinforced side with use of infrared radiation. The research program covered the total group of thirteen RC beams in the real scale. Six of them were strengthened with CFRP strip, the other six with SRP tape. The beams were heated by group of linear infrared radiators up to the measured in the adhesive layer temperature from $20^{\circ} \mathrm{C}$ to $80^{\circ} \mathrm{C}$. When the required test temperature was achieved, beams were loaded to failure in a four point bending test. First perceptible decrease in load capacity was observed around $50^{\circ} \mathrm{C}$. There was no mechanical anchoring of strengthening, therefore in all cases the damage was followed by delamination, at higher temperatures in the adhesive layer. Especially CFRP strengthened beams failed suddenly, without any characteristic noise symptoms of delamination. Their bearing capacity at temperatures above $65^{\circ} \mathrm{C}$ was close to the capacity of the not strengthened reference beam. SRP reinforced beams behaved somewhat better, mainly due to the greater width and therefore lower stress in the adhesive layer.

Keywords: composite strengthening, CFRP, SRP, glass transition temperature, epoxy resin, bond performance

Przestano do redakcji: 24.05.2017 $r$.

Przyjęto do druku: 01.09.2017 r. 